\title{
A Framework to Measure/Assess the Utility of Profiling as a Counter-Terrorism Tool Noel McGuirk
}

\begin{abstract}
The assessment of the usefulness of terrorist profiling is often conflated with an exaggerated presentation of the threat of terrorism as a basis to justify the use of terrorist profiling or an exaggerated impact of terrorist profiling as a basis to criticise its use by law enforcement officers. There is a considerable gap in the literature on terrorist profiling which fails to present a framework that can objectively engage in assessing/measuring the usefulness of terrorist profiling. The continued prevalence of terrorism continues to necessitate the existence of counterterrorism frameworks that allow law enforcement officers deploy pre-emptive control strategies. However, the difficulty posed by the existence of these strategies is whether they can actually be considered capable of assisting law enforcement officers detect, deter or prosecute those engaged in acts of terrorism or its associated preparatory activities.
\end{abstract}

This paper proposes to address this gap by firstly examining previous attempts at analysing the usefulness of terrorist profiling and the different approaches more generally adopted to measure the usefulness of counter-terrorism strategies. This discussion is followed by a presentation of a workable framework that can be applied to different manifestations of terrorist profiling to begin considering its usefulness as a counterterrorist tool. This paper ultimately concludes that any assessment of terrorist profiling requires an assessment of the processes used to construct profiles separately from the assessment of the application of terrorist profiling in the field with a further layer of assessing considering its broader impact to question its overall usefulness as a counterterrorism tool.

Key words: terrorist profiling; effectiveness; usefulness; framework; 


\section{Introduction}

The use of profiling as a counterterrorism tool has invoked considerable controversy as to whether it can ever be considered capable of assisting law enforcement officers detect, deter and prosecute those involved or likely to be involved in terrorism and/or its preparatory activities. The assessment of profiling raises complex issues as to what framework, if any, might be considered suitable to measure/test the utility of profiling as a counter-terrorism policing tool.

The central exploratory aim of this paper is to identify a framework capable of assessing/measuring the utility of terrorist profiling. The focus in this article is not on any one manifestation of terrorist profiling but rather it concreates on developing a system or analytical framework that can be applied to individual manifestations of terrorist profiling to assist in drawing conclusions about the likely utility of profiling. A core argument advanced in this paper is that the usefulness of terrorist profiling can only be demonstrated where a manifestation of profiling is capable of identifying likely terrorist characteristics that allows law enforcement officers draw distinctions between those likely to be involved in terrorism and/or its preparatory activities, the general population of law breaking and the general population at large.

This aim is pursued in three ways. The discussion begins firstly by presenting a working definition of terrorist profiling before secondly examining the weaknesses with the previous attempts at assessing the usefulness of terrorist profiling and counterterrorism strategies more broadly. Thirdly, the discussion then ultimately presents an objective framework that may be 
applied to individual manifestations of terrorist profiling so as to allow an assessment of the usefulness of terrorist profiling.

\section{A working definition of profiling}

Before embarking on analysing the previous attempts at measuring the usefulness of terrorist profiling, it is necessary to provide a definition at this juncture of 'profiling' to aid clarity throughout the paper.

Profiling may be considered as being a process that allows the profiler to identify a sequence of commonalities from different sets of data so as to predict likely offender characteristics. (Snook, et al, 2007). There is a lack of consensus in the literature as to the precise definition of profiling which sways between a narrow and a broad definitional approach. For the purposes of this paper, a broad definition of profiling is adopted so as to ensure that a significant array of profiling methods and approaches can be captured by any future use of the analytical framework proposed later in the paper. As a result, profiling is defined as being any technique or process that that seeks to allow law enforcement officers to identify probable offender characteristics. (Horvath, 2009).

The term profiling has become interchangeable with the terms 'offender profiling, criminal profiling, criminal personality profiling and psychological profiling' as a label for profiling techniques. (Douglas, et al, 1986, p. 405). Many methods use the same structure such as the analysis of crime scene evidence, victim reports and/or previous criminal records to identify common offender characteristics. The core differences lie in the abilities and the characteristics of the profiler and the use of the information by profilers to make predictions on likely offender characteristics. (Gendreau, et al, 2002). For example, some profiling methods may rely on forensic evidence to make predictions of likely characteristics, whilst other methods may use 
previous offending records to engage in statistical reasoning to identify commonalities to make predictions as to likely offender characteristics. Douglas et al identify that there are commonly three phases of profiling in criminal justice including: 'firstly, criminal investigation, secondly apprehension and thirdly prosecution'. (Douglas, et al, 1986, p. 404).

Consequently, the use of any data by a profiler so as to make predictions about 'likely offender characteristics can be considered some form of profiling' that may occur during criminal investigation, apprehension or prosecution of offenders. (Douglas, et al, 1986, p. 404).

\section{Previous Limitations/Difficulties with Analytical Frameworks Assessing/Measuring Terrorist Profiling}

Previous assessments on the usefulness of terrorist profiling raises a dichotomy between portraying profiling as an essential tool to assist law enforcement officers detect and prevent acts of terrorism and an unnecessary and unlawful practice capable of creating and perpetuating stereotypes which disproportionately affect ethnic and racial minorities in addition to stigmatising individuals who may have been previously involved in criminality. (Rosen, 2004).

For example, De Schutter and Ringleheim (2008), Moeckli (2005 \& 2012), Goldson (2006), Parmar (2010), Ojanen (2010 \& 2009) and Edley (2003) all examine the usefulness of terrorist profiling by conducting a legal assessment of the compatibility of terrorist profiling with various human rights standards and norms. Although human rights standards and norms may provide a basis to assess/measure the usefulness of terrorist profiling, an inherent limitation of this approach is that it frequently characterises terrorist profiling as being ineffective primarily on the basis of human rights norms and standards without undertaking a systematic identification, explanation or evaluation of the different profiling methods used to construct 
profiles. Further this literature does not specifically focus on the usefulness of these methodologies as a tool to assist law enforcement officers in identifying individuals engaged in terrorism and/or preparatory activities.

Alternatively, terrorist profiling has also been evaluated by conducting a utilitarian assessment of its capacity to assist law enforcement officers in detecting and preventing acts of terrorism. (Coke, 2003). This approach commonly characterises terrorist profiling as being useful on the basis of its necessity as part of counter-terrorism policy necessary to assist law enforcement officers to foil and intercept serious terrorist attacks prior to their commission. (Reddick, 2004). For example, a terrorist attack intercepted by law enforcement officers includes the attempted truck bombings in Singapore thought to have been targeting Singapore's airport, financial and embassy districts. (Rogers, 2003). However, this approach fails to identify the specific role fulfilled by terrorist profiling in comparison to other counter-terrorist measures in assisting law enforcement officers preventing and detecting terrorism. Any assessment of terrorist profiling which fails to identify the role played by terrorist profiling within counter-terrorism may be subject to the criticism that the assistive value of terrorist profiling may be over or under inflated in the prevention and detection of terrorism and as a result is unable to determine a realistic assessment/measurement of usefulness.

The usefulness of terrorist profiling has also been assessed/measured on the strength of moral arguments. This approach commonly characterises terrorist profiling as being ineffective on basis of empirical evidence, which demonstrates a negative impact of terrorist profiling on ethnic minority communities. For example, Swiney (2006) demonstrates the negative impact of terrorist profiling on Arab and Muslim communities by drawing on empirical research conducted on a selection of Arab and Muslim communities across the US since the September 
$11^{\text {th }} 2001$ attacks. This involved analysing empirical data collected from a range of Arab and Muslim community support centres across the US to identify common concerns in Arab and Muslim communities stemming from the use of terrorist profiling by law enforcement officers. This approach can also be considered limited as the assessment of usefulness is largely conducted on the basis of opinion canvassed from various communities as opposed to an enhanced investigation of the processes involved in constructing and applying terrorist profiles.

The problem with these previous assessments of terrorist profiling is that they tend to either support or reject terrorist profiling without undertaking a systematic assessment of the profiling methodologies that distinguishes between the construction and application of profiles. There is a distinct lack of debate, discussion and analysis in the literature that provides an analytical framework to assess/measure the usefulness of terrorist profiling which is capable of characterising terrorist profiling as being effective, ineffective or harmful on the basis of analysing the process of constructing terrorist profiles separate from the application of terrorist profiles. It is contended that the characterisation of terrorist profiling as being effective, ineffective or harmful can only be done by developing an analytical framework that is capable of assessing/measuring the usefulness of the profiling methods used in the construction of terrorist profiles separately from the application of terrorist profiles by law enforcement officers, as this provides a basis for a methodical and systematic investigation of the usefulness of terrorist profiling.

\section{Research Approaches in Examining the Usefulness of Counter-Terrorism Policies}

In light of the limitations of the previous attempts at analysing the usefulness of terrorist profiling, it is now appropriate to progress further by examining previous approaches or frameworks adopted more generally in counter-terrorism to measure/assess usefulness. It is 
significant to note that the literature on counter-terrorism does not present a universally accepted framework or approach to assess/measure the usefulness of counter-terrorism policies. (van Dongen, 2011) Consequently, the development of an analytical framework capable of assessing/measuring the usefulness of terrorist profiling can be considered challenging. Lum et al (2006, p. 510) argue that

there has been a proliferation of anti-terrorism programs and policies as well as massive increases in expenditures towards combating terrorism. Yet we currently know almost nothing about the effectiveness of any of these programmes.

Other academic commentators have also identified a significant gap in literature dealing with the issue of assessing/measuring the usefulness of counter-terrorism policies. (For example, van Dongen, 2011 Benmelech, et al, 2010 \& Gold, 2005).

Despite the inherent difficulty in assessing/measuring the usefulness of counter-terrorism, the literature presents two alternative approaches to assess/measure the usefulness of counterterrorism policies.

Firstly, a number of studies adopt quantitative approaches that concentrate on assessing the usefulness of counter-terrorism policies by employing statistical and mathematical techniques to demonstrate the impact of counter-terrorism policies. The quantitative approaches tend to assess/measure the usefulness of counter-terrorism policies by undertaking a utilitarian assessment of the results of specific counter-terrorism policies by analysing evidence of their capacity to curtail, disrupt or contain terrorism.

Secondly, a number of studies alternatively adopt qualitative approaches which assess the usefulness of counter-terrorism policies both by undertaking a utilitarian assessment of counter-terrorism policies but also present a number of arguments as to the reasons why 
particular counter-terrorism policies can be considered more useful in comparison to other counter-terrorism policies.

\section{Quantitative Approaches in Assessing Usefulness}

The assessment/measurement of usefulness in quantitative approaches commonly demonstrates effectiveness by concentrating on identifying the end result of the use of counterterrorism policies. This means that quantitative approaches commonly characterise counterterrorism policies as being useful if the study can demonstrate some evidence of success of the counter-terrorism policy's capacity to interfere, deter or prevent acts of terrorism. In essence, this approach can be considered similar to a utilitarian assessment of effectiveness. For example: Cauley and Im (1998) and Landes (1978) examined the usefulness of metal detectors and intervention policies used at airport and embassies to enhance security screening; Makovsky (2004) examined the usefulness of protecting terrorism sensitive buildings and installations through increased defence fortification measures; Enders and Sandler (1993) examined the usefulness of criminalising terrorism activities through anti-terrorism laws; Zussmann and Zussmann (2006) and Plaw (2008) examined the usefulness of 'targeted assassination' of 'known' terrorists; Dugan et al (2009) examined the usefulness of containment and curfew policies; and Testas (2004) examined the usefulness of the use of aggressive military retaliation policies as part of counter-terrorism policies.

An identifiable theme in these studies is that they engage in an assessment of usefulness by adopting a time series analysis of the individual counter-terrorism policy under investigation against the occurrence of terrorism so as to measure the impact of the individual counterterrorism policy. They tend to define the effectiveness of individual counter-terrorism policies by identifying indicators of success by reference to the stated aim of a particular counter- 
terrorism policy. This typically involves examining the impact of a policy in counteracting or minimising the risk of a known terrorism threat in isolation from other threats and other counter-terrorist policies over a period of time. As a result, this approach is a results driven assessment/measurement of usefulness.

A classic example can be considered Cauley and Im (1998) who examined the usefulness of metal detectors and other intervention counter-terrorism policies including enhanced security measures at embassies in counteracting the threat terrorism at airports and embassies from the 1950s to the 1970s. This involved adopting a time series analysis so as to plot the number of terrorist incidents at airports in the US and at embassies so as to demonstrate the impact of these intervention counter-terrorist policies in being able to manage the threat of terrorism. By mapping out the frequency and the occurrence of terrorism incidences and the introduction of intervention counter-terrorism policies the study was able to identify statistics which illustrated a fall in the occurrence of terrorism as a consequence of the intervention counter-terrorism policies.

Although these attempts at assessing/measuring the usefulness of terrorist profiling may be considered a valuable basis to characterise the usefulness of counter-terrorism policies, they ultimately fail to identify the value of any particular policy in assisting law enforcement officers in managing the threat of terrorism. The use of quantitative approaches to assess the usefulness of counter-terrorism raise at least three core weaknesses.

Quantitative research approaches tend to evaluate the usefulness of individual terrorist policies in isolation which fails to appreciate that law enforcement officers rarely employ counterterrorism policies in isolation or singly. Therefore, caution must be exercised in relying 
exclusively on quantitative research approaches to assess the usefulness of counter-terrorism policies as this approach could over or under inflate the role of the policy under investigation in the prevention and detection of terrorism.

Additionally, quantitative approaches carry the innate potential to assume that the capabilities of terrorist groups remain static over time. It is submitted that relying exclusively on quantitative research approaches requires caution not to over or under estimate the changing capabilities of terrorist groups and individuals.

Finally, any approach used to assess/measure usefulness which concentrates almost entirely upon the results of a counter-terrorism policy can be considered as being a very narrow assessment/measurement of usefulness as it fails entirely to consider the broader implications and consequences of using that policy to manage the threat of terrorism.

\section{Qualitative Approaches in Assessing Usefulness}

Other studies evaluating counter-terrorism regimes, such as those carried out by Charter (1994), Schmid and Crelinsten (1993), Art and Richardson (2007) and Cronin (2009) adopted qualitative approaches as a basis to identify the usefulness of individual policies within counter-terrorism regimes. The qualitative approach commonly seeks to evaluate the usefulness of counter-terrorism policies by adopting a two-stage analysis of counter-terrorism policies. Firstly, a broad investigation is commonly conducted of the counter-terrorism policy under investigation, and secondly a further study is conducted to hypothesise the factors governing the usefulness of that counter-terrorism policy. 
For example, Schmid and Crelinsten (1993) conduct an investigation into a broad range of counter-terrorism responses where they characterise counter-terrorism responses as either being 'soft' or 'hard' depending on the nature of the counter-terrorism response. After Schmid and Crelinsten (1993) develop their characterisation theory on counter-terrorism responses they further investigate whether their theory can be demonstrated by analysing the operation of different counter-terrorism responses in practice. In essence, Schmid and Crelinsten's investigation assesses the usefulness of counter-terrorism responses by firstly developing a theory on counter-terrorism policies and secondly progresses to examine the frequency of the occurrence of their theory in practice so that they are able to draw conclusions as to the factors that influence the usefulness of different counter-terrorism responses.

Therefore, qualitative approaches used to assess/measure the usefulness of counter-terrorism seeks to evaluate usefulness by not only concentrating on the results and capacity of counterterrorism to manage the threat of terrorism but also seek to analyse the broader implications of using particular counter-terrorism policies. However, all of the qualitative studies, similar to the quantitative studies, can be subject to criticism for failing to identify explicitly the role of individual counter-terrorism policies as being effective in assisting in managing the threat of terrorism. For example, Schmid and Crelinsten's (1993) study was ultimately incapable of characterising individual counter-terrorist responses as being effective, but rather was only capable of examining counter-terrorism responses as a whole. Despite this limitation, it is contended that qualitative approaches used to assess/measure usefulness may demonstrate a stronger basis to characterise any counter-terrorism policy as being effective, ineffective or harmful as it undertakes a broader assessment of not only the results of counter-terrorism policies but also assists in interpreting the results of counter-terrorism policies. 


\section{Summary of Qualitative and Quantitative Research Approaches}

The limitations of quantitative and qualitative approaches demonstrate that assessing/measuring the usefulness of counter-terrorism policies may be open to criticism on the basis that it can be considered challenging to examine single counter-terrorist policies in isolation. The challenge is due to the specific nature of counter-terrorism generally operating as a concert of policies in harmony to 'manage' the threat of terrorism. However, the mere fact that it can be considered challenging or limited does not invalidate the conclusions drawn in either the quantitative or qualitative studies, but rather this is a weakness that is attributable to the nature of counter-terrorism as opposed to the individual approaches. In particular, it is contended that these studies demonstrate that in developing an analytical framework to assess/measure the usefulness of terrorist profiling it is necessary to not only evaluate usefulness by the results of terrorist profiling but also part of the assessment/measurement of usefulness must include the broader impact and consequences of using terrorist profiling to assist in managing the threat of terrorism.

Although all of the studies investigating the usefulness of counter-terrorism policies may be subjected to criticism, the basis upon which the studies were conducted can be considered relevant in assisting with the creation of an analytical framework capable of assessing/measuring the usefulness of terrorist profiling.

In particular, it is significant to note that adopting purely quantitative approaches to assess the usefulness of terrorist profiling can be considered as being limited as it would fail to appreciate the broader implications of other counter-terrorism policies which are interdependent on the usefulness of terrorist profiling as a counter-terrorist policy. Therefore, any assessment of the usefulness of terrorist profiling must be conducted by using qualitative approaches in addition 
to quantitative approaches as a basis to evaluate usefulness as it provides a broader basis to assess/measure the usefulness of the construction and application of terrorist profiles by law enforcement officers. It is contended that by using quantitative and qualitative approaches at different stages in the assessment/measurement of usefulness, it creates a strong basis to characterise terrorist profiling as being effective, ineffective or harmful.

\section{An Analytical Framework to Assess/Measure the Usefulness of Terrorist Profiling}

The lack of coherence and consensus in the literature on the measurement/assessment of the usefulness of counter-terrorism policies demonstrates that it may be considered difficult to develop an analytical framework agreeable by many to examine the thorny issue as to how to measure/assess usefulness. Despite this difficulty, Van Um and Pisoiu (2011) present a helpful framework capable of assessing/measuring the usefulness of counter-terrorism policies by assessing the 'output, outcome and impact effectiveness' of the counter-terrorism policies through a combination of quantitative and qualitative approaches.

The 'output' can be defined as an assessment of the counter-terrorism measure; the 'outcome' can be defined as an assessment of the use of the counter-terrorism measure in managing the threat of terrorism, whereas the 'impact' can be defined as an assessment of the long-term consequences of the counter-terrorism measure. In the context of terrorist profiling the assessment of the 'output' involves analysing the construction of terrorist profiles, the assessment of the 'outcome' involving analysing the application of terrorist profiles and the assessment of the 'impact' involves examining the evidence of the long term impact on society of use of terrorist profiling in assisting in preventing and detecting terrorism. 
Although the terminology used by van Um and Pisoiu (2011) may be considered somewhat confusing and unnecessarily complex, the important point demonstrated from their framework is that in order to assess/measure the usefulness of a counter-terrorism measure it is necessary to undertake an examination of more than simply a utilitarian assessment of a counter-terrorism measure.

Consequently, the analytical framework below involves the assessment of terrorist profiling by concentrating on assessing/measuring effectiveness in three stages, which begins to address some of the inherent weaknesses of the previous attempts at evaluating the usefulness of terrorist profiling as discussed at the start of this paper.

\section{Output Effectiveness - Construction of Terrorist Profiles}

The first stage, the 'output effectiveness' assessment, involves concentrating on assessing how the counter-terrorism measure is constructed. Although 'output effectiveness' may be considered a useful label, this paper changes this terminology to 'input effectiveness' or the 'independent variables' that draw up the outputs of a terrorist profiling activity. This is due to the fact that at this first stage the entire approach is based on the inputting of data so as to construct profiles. In the context of terrorist profiling, it is contended that the assessment of the measure must begin by analysing the construction of a terrorist profile by focusing on analysing the profiling methods. This first stage in assessing/measuring usefulness can be largely considered a utilitarian assessment of terrorist profiling as it seeks to establish whether the profiling methods are capable of identifying likely terrorist characteristics.

A methodological assessment of the terrorist profiling can only be conducted in light of other more established criminal profiling methods. An assessment of the established criminal 
profiling methods, such as deductive and inductive profiling methodologies, may provide the first means of assessing/measuring the usefulness of terrorist profiling methodologies. It is contended that this first stage in assessing/measuring the usefulness of terrorist profiling could allow for conclusions to be drawn as to whether terrorist profiling is at minimum capable of identifying individuals likely to be engaged in terrorism or preparatory activities.

\section{Outcome Effectiveness - Application of Terrorist Profiles}

The second stage, the 'outcome effectiveness' assessment, involves assessing the use of the counter-terrorism measure in managing the threat of terrorism. Similar to the previous section, in order to use a label that more accurately reflects the nature of the assessment of profiling at this second stage of the terrorist profiling activity, the discussion throughout this paper refers to this stage as being the 'output effectiveness' or the 'dependent variable' that is dependent on the inputs at the previous stage in the terrorist profiling activity. This is due to the fact that this second stage is entirely focused on assessing the application of the constructed profiles by law enforcement officers.

This could involve considering factors such as arrests, prosecutions and investigations conducted as a result of the individuals identified by the application of terrorist profiles. The assessment of the application of terrorist profiles will primarily involve an empirical assessment of the application of terrorist profiles. This assessment would need to use quantitative research approaches to identify patterns and trends in the information whereas qualitative research approaches would be required to analyse any patterns or trends identified.

The assessment of terrorist profiling by examining the construction of terrorist profiles separately from the application of terrorist profiles by law enforcement officers can be 
considered a useful basis to characterise the usefulness of terrorist profiling as it seeks to assess/measure usefulness by focusing on the capability of terrorist profiling to produce results.

Undoubtedly, part of the assessment/measurement of the usefulness of terrorist profiling should involve an assessment as to whether terrorist profiling can actually work through an analysis of the construction and application of terrorist profiles. However, any analytical framework which purely assesses/measures usefulness by concentrating on its results can be considered as undertaking a narrow measurement/assessment of usefulness. A parallel may be drawn here to the discussion above on quantitative approaches, which criticised any assessment/measurement of usefulness purely on results as it denied a broader assessment/measurement of usefulness.

Therefore, any assessment/measurement of the usefulness of terrorist profiling through an examination of the profiling methods used in the construction of profiles and the application of profiles by law enforcement officers may be subject to the criticism that this approach fails to appreciate the broader consequences of terrorist profiling stemming from the use of terrorist profiling in the prevention and detection of terrorism. It is contended it is necessary to evaluate the usefulness of terrorist profiling by progressing to the third stage in order to characterise terrorist profiling as being 'effective, ineffective or harmful'. (Lum and Kennedy, 2012, pp. 34).

\section{Impact Effectiveness - The Consequences of Terrorist Profiling}

The final stage, 'the impact effectiveness' assessment involves examining the long-term impact by identifying the consequences of terrorist profiling as a counterterrorism tool. The previous two stages will be able to show, within a reasonable degree of probability, whether the various manifestations of terrorist profiling may be likely to work in theory and practice. However, in 
light of the very serious nature of terrorist profiling, it is argued that a narrow assessment of terrorist profiling by simply asking whether it works would fail to appreciate the broader consequences of using terrorist profiling which may be considered as eroding its usefulness as a counterterrorism policing tool.

As a result, it is contended that any assessment of the usefulness of terrorist profiling must question whether its long term consequences can be considered as being harmful and perhaps counterproductive to deterring, detecting and prosecuting those engaged in terrorism acts or its preparatory activities. At this stage in assessing/measuring the usefulness of an individual manifestation of terrorist profiling, it would be useful to consider other factors here that may have an impact on the assessment, such as considering the broader environment in which terrorism operates.

The purpose of the impact assessment is to question whether the cost and/or associated cost of terrorist profiling is likely to be considered as outweighing its perceived usefulness. It is acknowledged that in some cases, the assessment of the impact of terrorist profiling may be tentative which is due to inconclusive available evidence in the public domain. However, the discussion on impact should generally be able to discern whether the cost of an individual terrorist profiling scheme could be considered as eroding the state's moral authority to govern to the point that the cost of profiling is too much to pay in light of the danger it poses to fundamental human rights and democratic values in society.

Although it is accepted that the state has a right to adopt laws and policies to achieve its 'security', Teson's (2005) argument is also accepted that security in of itself cannot be viewed as being the end at the cost of fundamental human rights. Furthermore, if security 
becomes/remains the state's end focus then the continual denial of human rights will mean that the state begins to operate in the same field as the terrorists. This will create injustice and perceived injustice that will inevitably question the overall usefulness of terrorist profiling as a counterterrorism tool, which may be considered as denying the state its legitimacy to govern.

A further issue on assessing impact involves examining the lawfulness of including sensitive characteristics such as race, ethnicity, gender, religion etc in any form of profiling. The use of any terrorist profiling scheme will inevitably involve tensions between the protection of fundamental human rights and the need for security. However, from a legal perspective it is contended that any assessment on usefulness will need to be able to pinpoint the precise boundaries of acceptable (if any) forms of terrorist profiling.

\section{Conclusion: Measuring Usefulness}

The primary aim of the discussion in this paper was to present a framework capable of assessing/measuring the usefulness of individual manifestations of terrorist profiling schemes. Previous attempts at analysing the usefulness of terrorist profiling fall significantly short on engaging in a systematic analysis of the construction, application and impact of terrorist profiling. This creates a considerable gap in the literature as to how the usefulness of terrorist profiling might or should be undertaken.

In attempting to fill this gap, the discussion above contended that any systematic assessment of terrorist profiling requires separate analysis of the processes used to construct profiles versus the processes used to apply process. This provides a strong methodological basis to begin understanding the deficiencies and weaknesses (if any) that may exist in individual terrorist profiling schemes. However, it is also argued that a further layer of analysis that focuses on 
discerning the impact of terrorist profiling is required in order to determine an accurate assessment of the likely usefulness of terrorist profiling.

Therefore, it is argued that one framework that may be capable of conducting a systematic assessment of the usefulness of terrorist profiling is to engage in analysing the likely input effectiveness, output effectiveness and the impact effectiveness of each individual manifestation of terrorist profiling.

\section{References}

Benmelech, E., Berrebi, C. and Klor, E., (2010) 'Counter-Suicide-Terrorism: Evidence from House Demolitions.' NBER Working Paper No 16493.

Cauley, J. and Im, E., (1988) 'Intervention policy analysis of skyjackings and other terrorist incidents'. American Economic Review 78(2): 27.

Charter, D., (2994) The Deadly Sin of Terrorism: Its Effect on Democracy and Civil Liberty in Six Countries. London: Greenwood Press. 
Coke, T., (2003) 'Racial profiling post 9/11: Old story, new debate' in C. Brown (ed) Lost Liberties: Ashcroft and the Assault on Personal Freedoms. New York: New York Press.

Cronin, A., (2009) How Terrorism Ends: Understanding the Decline and Demise of Terrorist Campaigns. New Jersey: Princeton University Press.

de Schutter, O. and Ringelheim, J., (2008) 'Ethnic profiling: a rising challenge for European human rights law'. Modern Law Review 71(3): 358.

Douglas, J.,Ressler, R., Burgess, A. and Hartman, C., (1986) ${ }^{`}$ Criminal profiling from crime scene analysis'. Behavioural Science and Law 4: 401.

Edley, C., (2003) 'The New American Dilemma: Racial Profiling Post 9/11' in R. Leone and G. Anrig (eds), The War on Our Freedoms. New York: Public Affairs Publishing.

Enders, W. and Sandler, T., (2005) 'After 9/11: is it all different now?' Journal of Conflict Resolution 49: 259.

Enders, W. and Sandler, T., (2006) 'Distribution of transnational terrorism among countries by income, class and geography after 9/11'. International Studies Quarterly 367.

Enders, W. and Sandler, T., (2004) 'Is transnational terrorism becoming more threatening? A time- series investigation'. Journal of Conflict Resolution 44: 307. 
Enders, W. and Sandler, T., (2002) 'Patterns of transnational terrorism, 1970-1999: Alternative time- series estimates'. International Studies Quarterly 46: 145.

Enders, W. and Sandler, T., (1993) 'The Effectiveness of Anti-Terrorism Policies: A Vector- Autoregression-Intervention Analysis'. American Political Science Review 87(4): 829.

Gendreau, P., Goggin, C., Cullen, E. and Paparozzi, M., (2002) 'The common sense revolution and correctional policy' in J. Maguire, (ed) Offender rehabilitation and treatment: Effective programmes and policies to reduce reoffending. Oxford: John Wiley \& Sons Publishing.

Gold, D., "The Cost of Terrorism and the Costs of Countering Terrorism" (2005) International Working Affairs Papers, available at: $<<$ http://www.gpia.info/files/u1/wp/2005-03.pdf $>>$ (accessed 03rd May 2019).

Goldson, J., (2006) Ethnic Profiling and Counter-Terrorism: Trends, dangers and alternatives, 6th June 2006, available from:

$<<$ http://www.soros.org/initiatives/justice/articles publications/articles/counterterrorism_200 60606/goldston_20060606.pdf $>>$ (accessed 03rd May 2019).

Horvath, M., (2009) 'Offender Profiling' in S. Tong, R. Bryant and M. Horvath, Understanding Criminal Investigation. Oxford: John Wiley \& Sons Publishing.

Landes, W., (1978) 'An Economic Study of US Aircraft Hijackings, 1961-1976'. Journal of Law and Economics 21(1): 1. 
Lum, C. and Kennedy, L., (2012) 'Evidence-Based Counter-Terrorism Policy’ in C. Lum and L. Kennedy, Evidence-Based Counterterrorism Policy. London: Springer Publications.

Lum, C., Kennedy, L. and Sherley, A., (2006) 'Are counter-terrorist strategies effective? The results of the Campbell systematic review on counter-terrorism evaluation research'. Journal of Experimental Criminology 2: 489.

Moeckli, D., (2012) 'Anti-Terrorism Laws, Terrorist Profiling and the Right to NonDiscrimination' in A. Salinas De Frias, K. Samuel and N. White (eds), Counter-Terrorism: International Law and Practice. Oxford: Oxford University Press.

Moeckli, D., (2005) 'Discriminatory profiles: law enforcement after 9/11'. European Human Rights Law Review 5: 517.

Ojanen, T., (2010) 'Terrorist Profiling and Human Rights Concerns'. Critical Studies in Terrorism 3(10): 295.

Ojanen, T., (2009) 'Human Rights Dilemmas in Terrorist Profiling' in M. Scheinin (ed), Law and Security - Facing the Dilemmas. Florence: EUI Law. Available from:

$<<$ http://cadmus.eui.eu/bitstream/handle/1814/12233/LAW_2009 11.pdf? sequence=3>> (accessed 03rd May 2019).

Parmar, A., (2010) 'Policing and Ethnic Profiling' in K. Pall Sveinsson Ethnic Profiling: The Use of Race in UK Law Enforcement. London: Runnymede. 
Plaw, A., (2008) Targeting Terrorists: A Licence to Kill? London: Ashgate Publishing.

Reddick, R., (2004) 'Point: The case for profiling'. International Social Science Review 79: 154.

Rogers, P., (2003) 'The War on Terrorism: Winning or Losing'. ORG Briefing Paper, available at:

$<<$ http://www.oxfordresearchgroup.org.uk/publications/briefings/winningorlosing.htm $>>$ (accessed 3rd May 2019).

Rosen, J., (2004) The Naked Crowd: Reclaiming security and freedom in an anxious age. London: Random House.

Schmid, A. and Crelinsten, R., (1993) Western Responses to Terrorism. New York: Frank Cass Publishers.

Snook, B., Eastwood, J., Gendreau, P., Goggin, C. and Cullen, R., (2007) 'Taking Stock of Criminal Profiling: A Narrative Review and Meta-Analysis'. Criminal Science and Behaviour 34(4): 437.

Swiney, C., (2006) 'Racial Profiling of Arabs and Muslims in the US: Historical, Empirical and Legal Analysis Applied to the War on Terrorism'. Muslim World Journal of Human Rights $3(1): 1$.

Teson, F., (2005) 'Liberty Security' in R. Wilson (ed) Human Rights in the 'War on Terror'. 
Cambridge: Cambridge University Press.

Testas, A., (2004) 'Determinants of Terrorism in the Middle East'. Terrorism and Political Violence 16(2): 253.

van Dongen, T., (2011) 'Break it Down: An Alternative Approach to Measuring Effectiveness in Counter-Terrorism'. Journal of Applied Security Research 6: 357.

van Um, E. and Pisoiu, D., (2011) 'Effective Counterterrorism: What have we learned so far?' Economics of Security Working Paper 55, available at: $<<$ http://www.diw.de/documents/publikationen/73/diw 01.c.386651.de/diw_econsec0055.pd f $>$ (accessed 3rd May, 2019).

Zussmann, A. and Zussmann, N., (2006) 'Assassinations: Evaluating the Effectiveness of an Israeli Counter-terrorism Policing Using Stock Market Data'. Journal of Economic Perspectives 20(2): 193. 